\title{
Radiologic findings of pulmonary tuberculosis in adolescents
}

\author{
Authors \\ Clemax Couto \\ Sant'Anna ${ }^{1}$ \\ Christianne Mello \\ Schmidt ${ }^{2}$ \\ Maria de Fátima B \\ Pombo $\mathrm{March}^{3}$ \\ Susan Martins Pereira ${ }^{4}$ \\ Maurício Lima Barreto \\ ${ }^{1} \mathrm{PhD}$; Associate Professor; \\ Medical School of \\ Universidade Federal do \\ Rio de Janeiro - UFRJ \\ ${ }^{2}$ Master's Degree; \\ Physician of the Hospital \\ Universitário Antônio \\ Pedro, Universidade Federal \\ Fluminense - UFF \\ ${ }^{3} \mathrm{PhD}$; Adjunct Professor of \\ the Medical School, UFRJ \\ ${ }^{4} \mathrm{PhD}$; Associate Professor \\ of the Instituto de Saúde \\ Coletiva of Universidade \\ Federal da Bahia - UFBA \\ ${ }^{5} \mathrm{PhD}$ - Full Professor of the \\ Instituto de Saúde Coletiva, \\ UFBA
}

Submitted on: 05/14/2010

Approved on: 08/03/2010

Correspondence to:

Clemax Couto Sant'Anna

Rua Cinco de Julho,

350/604

Copacabana,

Rio de Janeiro, RJ

clemax@vetor.com.br

Financial Support: $\mathrm{CNPq}$

We declare no conflict of interest.

\begin{abstract}
Objective: To describe radiologic findings of pulmonary tuberculosis (TB) in adolescents. Methods: Retrospective, cross-sectional, observational study of 850 patients with TB, aged 10 to 19 years, and notified to the Brazilian Ministry of Health. Data were collected from the TB notification and medical records in the cities of Manaus, Amazonas State, and Salvador, Bahia State, in the 19962003 period. Data are shown in tables and analyzed using the chi-square and Mann-Whitney tests, with a 5\% significance level. Results: Mean age was 15.6 years; $443(52.1 \%)$ patients were males. The most common radiologic lesion was the upper pulmonary lobe infiltrate (53.3\%), and isolated cavitation was found in $32.4 \%$ of the patients. Both lungs were affected in $29.2 \%$ of the patients. The finding of bilateral radiologic lesions was significantly associated with longer disease duration $(\mathrm{p}=0.0005)$. Conclusions: Pulmonary TB in adolescents has similar characteristics to TB in adults, evidencing the important role played by adolescents in community disease transmission.
\end{abstract}

Keywords: tuberculosis; adolescents; diagnosis; chest radiography.

[Braz J Infect Dis 2011;15(1):40-44]@Elsevier Editora Ltda.

\section{INTRODUCTION}

Although the real situation of tuberculosis (TB) in adolescents is not well-known, children and adolescents account for $3 \%$ to $25 \%$ of the $\mathrm{TB}$ cases registered in different countries, with high frequencies in areas of high disease burden. ${ }^{1}$

In developed countries, TB affects mainly the elderly, but, in developing countries, the productive younger population is the most affected. ${ }^{2,3}$

Children play a limited role in TB transmission in the community, but adolescents can develop bacilliferous, thus, transmissible, pulmonary TB. ${ }^{4}$ Adolescents account for around 20\% of the Brazilian population. ${ }^{5}$ At that age, the individual is under development and undergoing behavioral and emotional changes, which can make adherence to treatment of prolonged diseases, such as TB, difficult. This can lead to treatment discontinuation, resulting in perpetuation of TB transmission in the community and appearance of resistant strains. Adolescents have greater social interaction and are more susceptible to illnesses and transmission of $\mathrm{TB}$ and other diseases.

This study aimed at assessing radiological aspects of pulmonary TB in Brazilian adolescents based on data of two Brazilian capital cities.

\section{METHODS}

This is a retrospective, descriptive, observational study. This study assessed TB notifications (individual investigation sheet of the Ministry of Health) of all adolescents living in the cities of Manaus and Salvador, diagnosed with TB and notified to the Brazilian Ministry of Health, from 1996 to 2005. Each notified case had the medical record located and scrutinized, along with the respective chest radiographic report present in the database of the BCG-Revac trial, ${ }^{6}$ which allowed the analysis of the radiologic patterns and their distribution according to age and disease duration. Radiologic patterns were adapted from Marais et al. ${ }^{4}$

The definition of adolescence of the World Health Organization that includes individuals aged 10 through 19 years, was adopted. Data of the original database were stored in the statistical software Epiinfo 6.0.

Statistical analysis was performed with the software SAS 6.04 (SAS Institute, Inc, Cary, North Carolina). The following tests were used: the Mann-Whitney non-parametric test for comparing continuous (numerical) variables 
between two subgroups; and the chi-square test for comparing categorical (categorical) variables. The significance level was 0.05 .

The BCG-Revac trial was approved by the Committees on Ethics in Research of the Universidade Federal da Bahia and by the London School of Hygiene and Tropical Medicine. ${ }^{6}$ As the present study used secondary data from the original project, a new approval by a Committee on Ethics in Research was not required.

\section{RESULTS}

Initially, the records of 904 adolescents were evaluated and $850(93.7 \%)$ patients who had chest radiography reports were included. Mean age was 15.6 years, and 443 (52.1\%) patients were male.

Table 1 shows the major characteristics of the chest radiographic findings.

The most frequent types of radiologic lesion were as follows: infiltrates (53.3\%); cavitation (32.4\%); and condensation $(27 \%)$. Hilar lymph node enlargement was found in $18 / 548(3.2 \%)$ of the cases, and atelectasis in $11 / 555(1.9 \%)$ of the cases. The TB radiologic lesions were in the right side in $220 / 476(42 \%)$ patients, bilateral in $139 / 476(29.2 \%)$, and in the left side in 137/476 (28.8\%) patients.

Age and the duration of disease until diagnosis were assessed in relation to unilateral or bilateral pulmonary radiologic involvement (Table 2).

A significant difference in disease duration until diagnosis was observed when the extension of the radiologic lesion was considered. The subgroup with bilateral lesion had significantly longer disease duration than the subgroup with unilateral lesion. On the other hand, no difference regarding age was observed in patients with unilateral or bilateral lesion when the total study sample was considered.

In the city of Manaus, the subgroup with bilateral lesions were significantly younger (13.7 years) than the subgroup with unilateral lesions (15.2 years). In the city of Salvador, patients with bilateral TB lesions were slightly older (16.4 versus 15.9 years) and had shorter duration of disease (median of 60 versus 30 days) than the subgroup with unilateral lesions.

Radiologic cavitation was more frequently found in patients aged from 16 to 19 years (36.1\%). No difference was observed regarding sex (Table 3 ).

Table 1. Major findings in chest radiography of adolescents with pulmonary tuberculosis. Cities of Manaus and Salvador. 1996-2005

\begin{tabular}{lccccccc}
\hline \multirow{2}{*}{ Variable } & & \multicolumn{2}{c}{ Total } & \multicolumn{2}{c}{ Manaus } & \multicolumn{2}{c}{ Salvador } \\
& Category & N & \% & N & \% & N & \% \\
\hline Chest radiography (performed) & Yes & 850 & 93.7 & 214 & 85.6 & 636 & 96.8 \\
& No & 57 & 6.3 & 36 & 14.4 & 21 & 3.2 \\
\hline Result of chest radiography & Normal & 38 & 6.2 & 8 & 7.1 & 30 & 6.0 \\
& Condensation & 165 & 27 & 39 & 34.8 & 126 & 25.3 \\
& Infiltrate & 325 & 53.3 & 49 & 43.8 & 276 & 55.4 \\
& Cavitations & 24 & 3.9 & 2 & 1.8 & 22 & 4.4 \\
& Pleural effusion & 37 & 6.1 & 10 & 8.9 & 27 & 5.4 \\
& Lymph node-pulmonary & 13 & 2.1 & 0 & 0.0 & 13 & 2.6 \\
& Miliary & 6 & 1 & 3 & 2.7 & 3 & 0.6 \\
\hline Isolated cavitations & Atelectasis & 2 & 0.3 & 1 & 0.9 & 1 & 0.2 \\
\hline Bilateral lesions & Yes & 183 & 32.4 & 19 & 19.2 & 164 & 35.3 \\
& No & 381 & 67.6 & 80 & 80.8 & 301 & 64.7 \\
\hline Pleural effusion & Yes & 139 & 29.2 & 20 & 23.8 & 119 & 30.4 \\
& No & 337 & 70.8 & 64 & 76.2 & 273 & 69.6 \\
\hline & Yes & 53 & 9.3 & 13 & 12.4 & 40 & 8.6 \\
& No & 518 & 90.7 & 92 & 87.6 & 426 & 91.4 \\
\hline
\end{tabular}


Table 2. Distribution of the adolescents with pulmonary tuberculosis according to age and duration of disease in the general sample and radiologic location (unilateral vs. bilateral), in the cities of Salvador and Manaus. 1996-2005

\begin{tabular}{lcccccccc}
\hline Variable & Radiologic & N & Mean & SD & Median & Minimum Maximum & P value \\
& location & & & & & & & \\
\hline Total & & & & & & & & \\
Age (years) & Unilateral & 337 & 15.8 & 2.2 & 16 & 10 & 19 & 0.14 \\
& Bilateral & 139 & 16.0 & 2.3 & 16 & 10 & 19 & \\
Disease duration (days) & Unilateral & 266 & 58.5 & 67.3 & 30 & 2 & 730 & 0.0005 \\
& Bilateral & 108 & 76.8 & 68.7 & 60 & 7 & 365 & \\
\hline Manaus & & & & & & & & \\
Age (years) & Unilateral & 64 & 15.2 & 1.5 & 15 & 11 & 18 & 0.002 \\
& Bilateral & 20 & 13.7 & 2.2 & 13.5 & 10 & 18 & \\
Disease duration (days) & Unilateral & 61 & 61.6 & 51.7 & 45 & 5 & 300 & 0.30 \\
& Bilateral & 19 & 92.3 & 92.2 & 60 & 14 & 360 & \\
\hline Salvador & & & & & & & & 0.037 \\
Age (years) & Unilateral & 273 & 15.9 & 2.3 & 16 & 10 & 19 & \\
& Bilateral & 119 & 16.4 & 2.1 & 17 & 10 & 19 & \\
Disease duration (days) & Unilateral & 205 & 57.6 & 71.3 & 30 & 2 & 730 & 0.0004 \\
& Bilateral & 89 & 73.5 & 62.8 & 60 & 7 & 365 &
\end{tabular}

SD, standard deviation

Table 3. Distribution of the radiologic finding cavitation according to age bracket and sex. 1996-2005

\begin{tabular}{|c|c|c|c|c|c|}
\hline \multirow[t]{2}{*}{ Variable } & \multicolumn{2}{|c|}{ Yes } & \multicolumn{2}{|c|}{ No } & \multirow[t]{2}{*}{$P$ value } \\
\hline & $\mathrm{N}$ & $\%$ & $\mathrm{~N}$ & $\%$ & \\
\hline \multicolumn{6}{|c|}{ Total of cases } \\
\hline Age (years) & & & & & 0.031 \\
\hline 10 to 15 & 67 & 27.6 & 176 & 72.4 & \\
\hline 16 to 19 & 116 & 36.1 & 205 & 63.9 & \\
\hline Sex & & & & & 0.18 \\
\hline Male & 77 & 29.7 & 182 & 70.3 & \\
\hline Female & 106 & 35.0 & 197 & 65.0 & \\
\hline \multicolumn{6}{|l|}{ Manaus } \\
\hline Age (years) & & & & & 0.49 \\
\hline 10 to 15 & 11 & 17.2 & 53 & 82.8 & \\
\hline 16 to 19 & 8 & 22.9 & 27 & 77.1 & \\
\hline Sex & & & & & 0.8 \\
\hline Male & 7 & 18.0 & 32 & 82.1 & \\
\hline Female & 12 & 20 & 48 & 80 & \\
\hline \multicolumn{6}{|l|}{ Salvador } \\
\hline Age (years) & & & & & 0.15 \\
\hline 10 to 15 & 56 & 31.3 & 123 & 68.7 & \\
\hline 16 to 19 & 108 & 37.8 & 178 & 62.2 & \\
\hline Sex & & & & & 0.12 \\
\hline Male & 70 & 31.8 & 150 & 68.2 & \\
\hline Female & 94 & 38.7 & 149 & 61.3 & \\
\hline
\end{tabular}




\section{DISCUSSION}

In Brazil, data on the incidence of TB in adolescents (individuals aged from 10 to 19 years) provided by the Ministry of Health became available in 1999. For that age bracket and from 1999 to 2005, the incidence of TB ranged from 91.53 to $36.44 / 100,000$ inhabitants in the city of Salvador and from 70.12 to 45.65/100,000 inhabitants in the city of Manaus. ${ }^{7}$

The present study showed a predominance of characteristic lesions of re-infection or adult type TB in the adolescents assessed: $53 \%$ of chest $\mathrm{x}$-rays had infiltrates in the upper third of the lungs, and $32 \%$ of the radiographs showed cavitations. In addition, most patients with cavitations were adolescents in the postpubertal stage (median of age, 16 years), a situation compatible with primo-infection occurring early in childhood.

Chest radiograph was largely used in the services of the National TB Control Program emphasizing the importance of imaging diagnosis in health care services in Brazil.

Radiologic patterns of pulmonary TB allow us to infer several aspects of the pathogenesis and clinical picture of the patients assessed. Classically, there are two presentations of TB: primo-infection or primary $\mathrm{TB}$, and reinfection. The former is more commonly found during childhood, and is characterized by uni- or bilateral hilar lymph node enlargement either in association or not with pulmonary infiltrates. ${ }^{4}$ Likewise, hematogenous disseminations, also found in TB primo-infection, radiologically expressed as disseminated micronodular infiltrates, known as the miliary pattern. ${ }^{8}$ In the present study, the primary TB presentation classified as lymph node-pulmonary, primary complex, and miliary added up to over $3 \%$ of the total. It is evident that the adolescents here studied had already developed TB primo-infection prior to the disease that made them look for health care.

In Brazil and in other countries with a high TB burden, TB primo-infection and primary $\mathrm{TB}$ are more common in children than in adults, because of the high likelihood of contact with M. tuberculosis during childhood. In developed countries, the likelihood of developing TB primo-infection can be postponed to adolescence or adulthood. ${ }^{8,9}$

Individuals who had TB primo-infection or had been vaccinated with BCG develop a type of immunogenic defense that, when exposed to a bacillary burden originating from a contagious source, relies on the immune memory to trigger phagocytosis of the bacilli, which then entry a state of metabolic inactivity. ${ }^{10,11}$ If the immune system fails re-infection or adult-type TB can occur. In such cases, the chest radiograph shows characteristic infiltrates and cavitations in the upper pulmonary thirds, usually in the posterior segments. The most severe radiologic forms of re-infection TB appear as extensive bilateral lesions, cavitations, and bronchial dissemination of the disease. ${ }^{8}$
In this study, cavitations were more common in adolescents aged 16 years or older, while lymph nodes enlargement were more common in patients aged 15 years or less. This distribution confirms the classical notion that more suggestive forms of primary TB occur in younger individuals and post-primary manifestations in older adolescents. The same analysis regarding sex, showed no difference.

Pleural effusion due to TB, more common in adolescents and adults than in children, was observed in $9 \%$ of the patients.

In this study, the most severe TB lesions were related to the longer duration of symptoms, possibly due to a diagnosis delay in health services. The effectiveness of TB control programs can be assessed through the delay to establish $\mathrm{TB}$ diagnosis. ${ }^{11}$ In our study, the median of symptom duration was 60 days, suggesting a high risk for patients to infect their families and close contacts. In addition, the maximum delay for the diagnosis was 365 days for patients with bilateral lesions, and 730 days for patients with unilateral lesions. In the case of adolescents who can cough and expectorate, sputum bacilloscopy can provide earlier diagnosis. ${ }^{12}$

Patients from the city of Manaus had TB forms of faster evolution and at a younger age than patients from the city of Salvador. This may have been due to the high frequency of non-tuberculous mycobacteria in the Amazon region. In addition, factors related to the host, low effectiveness of BCG vaccination, or, more likely, the characteristics of $M$. tuberculosis could explain such findings. ${ }^{6,13}$

On the other hand, in the city of Salvador, the disease lasted longer for older patients. This suggests that the health services are having problems to detect TB cases, which can result in a long interval for establishing the diagnosis.

This study had some limitations. One concern is the lack of information about some variables, such as radiographic reports and demographic data, that, however, had a small influence in the final results, considering the large number of cases. Tuberculosis notification in countries where TB is endemic offers innumerous difficulties to TB control programs. ${ }^{11}$ Similarly, comparison of our data with those reported in the literature could not be done as most studies in countries where TB is endemic and affects adolescents do not allow for separate analysis of that age group. TB control programs around the world use the cut-off point of 15 years to categorize patients as children or adults, and, thus, data referring to adolescents (over 10 years of age) can not be retrieved. In addition, this study could not assess the social conditions of the adolescents analyzed based on the data found in their notification sheet. However, it is known that, in Brazil and other countries where TB is endemic, most patients belong to the most vulnerable extract of society.

In conclusion, most cases of TB in adolescents were similar to those in adults: apical pulmonary infiltrates, extensive lesions, and cavitations. Primary TB forms were rare. ${ }^{14} \mathrm{In}$ general, the duration of the disease until diagnosis was rather 
prolonged. This delay may have accounted for the finding of severe lesions in many patients. Adolescents belong to a group that deserves special attention from health care providers, either due to their difficulty in adhering to prolonged treatments or to their reluctance to look for medical care. Thus, further efforts are recommended to improve the efficacy of the health care network for diagnosing TB and to provide more information regarding the complaints suggestive of $\mathrm{TB}$ in adolescents, aiming at earlier diagnosis of the disease.

\section{ACKNOWLEDGEMENTS}

The authors thank Profs. Gesmar V Haddad and Adauto Dutra of the Post-graduation Program in Pediatrics of the Universidade Federal Fluminense, city of Niterói, state of Rio de Janeiro.

\section{REFERENCES}

1. Hesseling AC, Schaaf HS, Gie RP et al. A critical review of diagnosis approaches in the diagnosis of childhood tuberculosis. Int J Tuberc Lung Dis. 2002; 6:1038-1045.

2. Donald PR. Childhood tuberculosis: the hidden epidemic. Int J Tuberc Lung Dis. 2004; 8:627-629.

3. Marais BJ, Graham SM, Cotton MF, Beyers N. Diagnosis and management challenges for childhood tuberculosis in the era of HIV. J Infect Dis. 2007; 196,supl. 1:76-85.

4. Marais BJ, Gie RP, Schaaf HS et al. The natural history of childhood intra-thoracic tuberculosis: a critical review of literature from the pre-chemotherapy era. Int J Tuberc Lung Dis. 2004; 8:392-402.
5. Brasil. IBGE/Censos demográficos. População total. Distribuição (\%) por faixa etária segundo unidade da federação, 2006. Available at <http://tabnet.datasus.gov.br/cgi/ tabcgi.exe?idb2007/a01.def>. Accessed on: 1 Oct. 2009.

6. Rodrigues LC, Pereira SM, Cunha SS et al. Effect of BCG revaccination on incidence of tuberculosis in school-aged children in Brazil: the BCG-REVAC cluster-randomised trial. Lancet 2005; 366:1290-1295.

7. Brasil. Ministério da Saúde, SVS, SINAM. Indicadores de morbidade e fatores de risco. Taxa de incidência de tuberculose por faixa etária segundo Unidade da Federação. Brasília, 2007b. Available at <http://tabnet.datasus.gov.br/ cgi/tabcgi.exe?idb2007/d0202.def> Accessed on: 21 Oct. 2009.

8. Sant'Anna CC. Tuberculose na criança. J. Pediatr. (Rio J.) 1998; 74(Supl.1):S69-S75.

9. Styblo K. Estado del arte, I: epidemiologia de la tuberculosis. Bol UICT 1978; 53:145-147.

10. Barroso EW. Imunopatogenia. In: Sant'Anna CC (ed). Tuberculose na infância e na adolescência. São Paulo: Atheneu, 2002.

11. Procópio MJ (Coord.). Controle da Tuberculose - Uma Proposta de Integração Ensino - Serviço. Rio de Janeiro: EAD/ENSP, 2008.

12. Sociedade Brasileira de Pneumologia e Tisiologia. III Diretrizes para tuberculose da Sociedade Brasileira de Pneumologia e Tisiologia. J Bras Pneumol. 2009; 35:1018-1048

13. Salem JI, Marója MF, Carvalho FF, Lima MO et al. Valor relativo do exame direto, após concentração e por cultivo de escarro no diagnóstico bacteriológico da tuberculose pulmonar no Amazonas. J. Pneumol. 1990; 16:133-136

14. Sant'Anna CC, March MF, Barreto M, Pereira S, Schmidt C. Pulmonary tuberculosis in adolescents: radiographic features. Int J Tuberc Lung Dis. 2009; 13:1-3. 